\title{
Short Communication: Allele, Genotype, and Haplotype Data for Bovine Spongiform Encephalopathy-Resistance Polymorphisms from Healthy US Holstein Cattle ${ }^{1}$
}

\author{
B. W. Brunelle, ${ }^{\star}$ M. E. Kehrli Jr., ${ }^{\star}$ J. R. Stabel,† D. Moody Spurlock,ł L. B. Hansen,§ and E. M. Nicholson*2 \\ "Virus and Prion Diseases of Livestock Research Unit, and \\ †Bacterial Diseases of Livestock Research Unit, National Animal Disease Center, USDA, Agricultural Research Service, Ames, IA 50010 \\ łDepartment of Animal Sciences, lowa State University, Ames 50011 \\ $\S$ Department of Animal Science, University of Minnesota, St. Paul 55108
}

\begin{abstract}
Bovine spongiform encephalopathy (BSE) is a neurodegenerative disease of cattle caused by abnormally folded prion proteins. Two regulatory region polymorphisms in the bovine prion gene are associated with resistance to classical BSE disease: a 23-bp region in the promoter that contains a binding site for the repressor protein RP58, and a 12-bp region in intron 1 that has a binding site for the transcription factor SP1. The presence of these binding sites enhances BSE resistance in cattle, whereas cattle that lack these regions are more susceptible to the disease. The present study examined the allele, genotype, and haplotype frequencies for the 23-bp and 12-bp polymorphisms in Holstein cattle from 9 different US states, and these frequencies were compared with data previously established for Holstein cattle from the United Kingdom, Germany, and Japan. Additionally, the coding region of the prion gene was sequenced from the US samples. Finally, archival samples from US Holstein sires born between 1953 and 1957 were analyzed. We found that the resistant allele and genotype frequencies for the US Holstein cattle were as high, or higher, relative to that observed in other countries. Furthermore, the current US frequencies were comparable to those determined in the archival samples from the $1950 \mathrm{~s}$. Based on the frequencies of these regulatory region polymorphisms, the US Holstein population is not at a greater risk for BSE than Holsteins worldwide.
\end{abstract}

Key words: bovine spongiform encephalopathy, genetics, Holstein, prion

\footnotetext{
Received June 6, 2007.

Accepted October 9, 2007.

${ }^{1}$ Disclaimer: Mention of trade names or commercial products in this article is solely for the purpose of providing specific information and does not imply recommendation or endorsement by the US Department of Agriculture.

${ }^{2}$ Corresponding author: eric.nicholson@ars.usda.gov
}

Transmissible spongiform encephalopathies (TSE) are a class of fatal neurodegenerative diseases caused by abnormally folded prion proteins that induce templated refolding of normal cellular host prion proteins into the abnormal, infectious form (Prusiner, 1998). Bovine spongiform encephalopathy (BSE) is a TSE of cattle and is spread through ingestion of BSE-contaminated feedstuffs (Wilesmith et al., 1991). Although no AA differences in the cattle prion protein have been reported to influence BSE disease, 2 noncoding polymorphisms upstream of the bovine PRNP coding region have been associated with BSE resistance (Sander et al., 2004; Juling et al., 2006). The first polymorphism is a 23-bp insertion/deletion (indel) located in the $P R N P$ promoter and contains a binding site for the repressor protein RP58, and the second is a 12-bp indel in the first intron that contains a binding site for the SP1 transcription factor protein (Hills et al., 2001; Sander et al., 2004). Deletions at these sites remove the regulatory regions, and, based upon reporter gene assays, increase the expression levels of the host prion protein (Sander et al., 2005). This is important because increased prion protein expression is a factor known to enhance progression of a TSE disease (Carlson et al., 1994; Manson et al., 1994). Thus, cattle homozygous for the insertions are considered to be more resistant than cattle that have deletions at these sites.

The goal of the present report was to determine the allele, genotype, and haplotype frequencies of the 23bp and 12-bp indels of Holstein cattle from 9 US states. To assess if there was variation in frequencies between different Holstein populations, the total sampled US population was then compared with each state and to published data of Holstein cattle from the United Kingdom, Germany (Juling et al., 2006), and Japan (Nakamitsu et al., 2006). Given the influence that coding region differences can have on TSE susceptibility, the PRNP coding region was also sequenced to identify any polymorphisms. It is beneficial to know the prevalence of the indel and coding-region polymorphisms in cattle 
populations because such knowledge is useful in comparing levels of resistance among different populations, as well as establishing the baseline of a population if an increase in the allele frequency was considered desirable.

Three sources of US Holstein cattle were used to obtain DNA representing 700 head of cattle. Buccal swabs, blood, or both were collected from a total of 130 head of cattle from the I-O-State Dairy, owned and managed by Iowa State University. The second source was a subset of DNA samples originally collected for the National Animal Health Monitoring System (NAHMS) Dairy 96 Study (Ott et al., 1999). Briefly, the original study consisted of collecting random samples from dairy farms in 20 states for the purposes of animal health monitoring. From this collection, 560 Holstein samples were selected at random from 32 farms in 9 states for use in this study: California (4 farms; 60 head), Iowa (4; 45), Minnesota (3; 44), New York (4; 82), Oregon (4; $58)$, Tennessee $(2 ; 52)$, Texas $(3 ; 76)$, Vermont $(3 ; 84)$, and Wisconsin $(5 ; 59)$. The third source consisted of frozen semen from 10 Holstein sires born in the United States between 1953 and 1957.

Extraction, amplification, genotyping, and sequencing of DNA were carried out as previously described (Brunelle et al., 2007). Briefly, DNA was extracted from blood, buccal swabs, and semen using the High Pure PCR Template Preparation Kit (Roche Applied Science, Indianapolis, IN). Polymerase chain reaction primer pairs were used to amplify a 130 - to 153 -bp region surrounding the 23-bp promoter indel, a $190-$ to $202-b p$ region containing the 12-bp intron 1 indel, and a 986 bp region surrounding the $P R N P$ coding region in cattle. Genotypes were readily distinguished on a $4 \%$ NuSieve gel (Cambrex, Rockland, ME) by visual inspection of molecular mass verified against a 100-bp DNA marker (Promega, Madison, WI). The PRNP coding region was sequenced, and the results were submitted to GenBank (accession numbers EF626036 to EF626529). Haplotypes were determined using Haploview 3.32 (Barrett et al., 2005). Statistical analyses were performed using GraphPad Prism 4 (Graphpad Software Inc., San Diego, CA). Fisher's exact test (Lange et al., 1988) was used to test for differences between allele frequencies, and the $\chi^{2}$ test was used to test for differences between genotype frequencies, as well as between haplotype frequencies.

Holstein cattle in 9 US states were found to have a range of allele, genotype, and haplotype frequencies for the 23-bp and 12-bp indels, but very few states had frequencies that were significantly different compared with the total sampled US Holstein population (Tables 1 to 3 ). For the haplotype data, it is worth noting that the majority of haplotypes exhibited either an insertion at both the 23-bp and 12-bp loci, or a deletion at both the 23-bp and 12-bp loci. However, there was a minor haplotype that consisted of a 23-bp deletion and a 12bp insertion that occurred at an average frequency of 0.04 , with a range of 0.00 to 0.08 . This haplotype was not found to occur twice in an animal, which would have resulted in a diplotype that was homozygous for the 23-bp deletion and homozygous for the 12-bp insertion. The inverse of the minor haplotype, a 23-bp insertion and a 12-bp deletion, was not observed. Overall, the ranges observed for the allele, genotype, and haplotype frequencies likely reflect regional differences in sire selection in breeding programs on commercial dairies.

To identify differences in allele, genotype, and haplotype frequencies for the 23-bp and 12-bp polymorphisms between Holsteins in the United States and in other countries, the sampled US Holstein population was compared with previously published data. In one study, healthy Holsteins from Germany and the United Kingdom had been selected to be contemporaneous and geographically matched to BSE-positive Holsteins (Juling et al., 2006). In another study, Japanese Holstein samples had been collected from 8 dairy farms and 1 slaughterhouse with no indicated match to BSE-positive Holsteins (Nakamitsu et al., 2006).

Holstein cattle in the United States had a significantly higher frequency of 23-bp insertion and 12-bp insertion alleles, as well as homozygous insertion genotypes, compared with Holstein cattle in the United Kingdom and Japan (Tables 1 and 2). The allele and genotype frequencies were similar between the US and German Holsteins, although the US frequencies were always greater than or equal to that from Germany (Tables 1 and 2). The minor haplotype, which contained the 23-bp deletion and 12-bp insertion alleles, was found at a similar frequency in Holsteins from the UK (0.08) and Germany (0.09), both of which were greater than that observed in the US (0.04; Table 3). Haplotype data for the Japanese Holsteins were not available. These differences were surprising given the use of semen from US Holstein sires in all 4 countries. However, these differences may result from a founder population effect in each country before the extensive use of semen from US Holstein sires.

No novel polymorphisms were detected within the $P R N P$ coding region from 494 US Holstein cattle as all have been previously reported (Seabury et al., 2004). Overall, 3 nucleotide sites contained a substitution within the 795-bp coding region (nucleotides $234 \mathrm{~A} / \mathrm{G}$, $339 \mathrm{C} / \mathrm{T}, 576 \mathrm{C} / \mathrm{T}$ ), none of which led to a change in the encoded AA sequence. The octapeptide repeat region of the prion protein in cattle can consist of 5,6 , or 7 repeats. Although no association has been made in cattle 
BRUNELLE ET AL.

Table 1. Frequencies of the 23-bp and 12-bp alleles in Holstein cattle

\begin{tabular}{|c|c|c|c|c|c|c|c|c|}
\hline & \multicolumn{4}{|c|}{$23 \mathrm{bp}$} & \multicolumn{4}{|c|}{$12 \mathrm{bp}$} \\
\hline & $\mathrm{n}$ & + & - & $P$-value ${ }^{1}$ & $\mathrm{n}$ & + & - & $P$-value ${ }^{1}$ \\
\hline \multicolumn{9}{|l|}{ State } \\
\hline California & 120 & 0.55 & 0.45 & $0.017^{*}$ & 120 & 0.55 & 0.45 & 0.127 \\
\hline Iowa & 350 & 0.45 & 0.55 & 0.588 & 350 & 0.49 & 0.51 & 0.590 \\
\hline Minnesota & 88 & 0.31 & 0.69 & $0.020^{*}$ & 88 & 0.39 & 0.61 & 0.123 \\
\hline New York & 164 & 0.45 & 0.55 & 0.803 & 164 & 0.49 & 0.51 & 0.804 \\
\hline Oregon & 116 & 0.40 & 0.60 & 0.437 & 116 & 0.41 & 0.59 & 0.175 \\
\hline Tennessee & 104 & 0.38 & 0.63 & 0.259 & 104 & 0.38 & 0.62 & 0.083 \\
\hline Texas & 152 & 0.46 & 0.54 & 0.548 & 152 & 0.54 & 0.46 & 0.146 \\
\hline Vermont & 168 & 0.43 & 0.57 & 0.934 & 168 & 0.49 & 0.51 & 0.744 \\
\hline Wisconsin & 118 & 0.42 & 0.58 & 0.700 & 118 & 0.44 & 0.56 & 0.502 \\
\hline US total & 1,380 & 0.43 & 0.57 & - & 1,380 & 0.47 & 0.53 & - \\
\hline \multicolumn{9}{|l|}{ Country } \\
\hline Germany $^{2}$ & 626 & 0.38 & 0.62 & $0.035^{*}$ & 618 & 0.47 & 0.53 & 0.846 \\
\hline United Kingdom ${ }^{2}$ & 552 & 0.29 & 0.71 & $<0.001^{*}$ & 540 & 0.37 & 0.63 & $<0.001^{*}$ \\
\hline Japan $^{3}$ & 556 & 0.21 & 0.79 & $<0.001^{*}$ & 580 & 0.26 & 0.74 & $<0.001^{*}$ \\
\hline \multicolumn{9}{|l|}{ Archived } \\
\hline US 1950s & 20 & 0.35 & 0.65 & 0.503 & 20 & 0.55 & 0.45 & 0.510 \\
\hline
\end{tabular}

${ }^{1}$ Statistical comparisons between total US population and individual states, countries, and archived samples using Fisher's exact test.

${ }^{2}$ Juling et al. (2006).

${ }^{3}$ Nakamitsu et al. (2006).

$* P<0.05$.

with 5 or 6 repeats (Hunter et al., 1994; Sander et al., 2004), it has been observed that transgenic mice expressing cellular bovine prion proteins with 7 or 10 of these repeats were more susceptible to disease after inoculation with BSE (Castilla et al., 2004, 2005). Brown Swiss cattle are the only breed to date that have been found to carry alleles with 7 octapeptide repeats
(Schlapfer et al., 1999; Seabury et al., 2004), and they appear to be more susceptible to BSE (Geldermann et al., 2006; Sauter-Louis et al., 2006). Of the 494 cattle that were sequenced at the $P R N P$ coding region, 457 were homozygous for 6 octapeptide repeats, and 38 were heterozygous for 5 and 6 octapeptide repeats. No animals had a sequence with a 7 -octapeptide repeat region,

Table 2. Frequencies of the 23-bp and 12-bp genotypes in Holstein cattle

\begin{tabular}{|c|c|c|c|c|c|c|c|c|c|c|}
\hline & \multicolumn{5}{|c|}{$23 \mathrm{bp}$} & \multicolumn{5}{|c|}{$12 \mathrm{bp}$} \\
\hline & $\mathrm{n}$ & $+/+$ & $+/-$ & $-1-$ & $P$-value ${ }^{1}$ & $\mathrm{n}$ & $+/+$ & $+1-$ & $-1-$ & $P$-value ${ }^{1}$ \\
\hline \multicolumn{11}{|l|}{ State } \\
\hline California & 60 & 0.28 & 0.53 & 0.18 & $0.047^{*}$ & 60 & 0.28 & 0.53 & 0.18 & 0.257 \\
\hline Iowa & 175 & 0.17 & 0.57 & 0.26 & 0.303 & 175 & 0.22 & 0.55 & 0.23 & 0.423 \\
\hline Minnesota & 44 & 0.07 & 0.48 & 0.45 & 0.057 & 44 & 0.09 & 0.59 & 0.32 & 0.108 \\
\hline New York & 82 & 0.22 & 0.45 & 0.33 & 0.573 & 82 & 0.24 & 0.49 & 0.27 & 0.935 \\
\hline Oregon & 58 & 0.19 & 0.41 & 0.40 & 0.338 & 58 & 0.19 & 0.43 & 0.38 & 0.251 \\
\hline Tennessee & 52 & 0.17 & 0.40 & 0.42 & 0.231 & 52 & 0.19 & 0.38 & 0.42 & 0.078 \\
\hline Texas & 76 & 0.22 & 0.47 & 0.30 & 0.658 & 76 & 0.36 & 0.37 & 0.28 & $0.028^{*}$ \\
\hline Vermont & 84 & 0.12 & 0.62 & 0.26 & 0.131 & 84 & 0.20 & 0.57 & 0.23 & 0.424 \\
\hline Wisconsin & 59 & 0.19 & 0.46 & 0.36 & 0.736 & 59 & 0.20 & 0.47 & 0.32 & 0.749 \\
\hline US total & 690 & 0.18 & 0.51 & 0.31 & - & 690 & 0.23 & 0.50 & 0.28 & - \\
\hline \multicolumn{11}{|l|}{ Country } \\
\hline Germany $^{2}$ & 313 & 0.15 & 0.47 & 0.38 & 0.081 & 309 & 0.22 & 0.50 & 0.28 & 0.974 \\
\hline United Kingdom ${ }^{2}$ & 276 & 0.05 & 0.49 & 0.46 & $<0.001^{*}$ & 270 & 0.11 & 0.52 & 0.37 & $<0.001^{*}$ \\
\hline Japan $^{3}$ & 278 & 0.05 & 0.32 & 0.63 & $<0.001^{*}$ & 290 & 0.07 & 0.38 & 0.55 & $<0.001^{*}$ \\
\hline \multicolumn{11}{|l|}{ Archived } \\
\hline US 1950s & 10 & 0.10 & 0.50 & 0.40 & 0.738 & 10 & 0.20 & 0.70 & 0.10 & 0.374 \\
\hline
\end{tabular}

${ }^{1}$ Statistical comparisons between total US population and individual states, countries, and archived samples using the $\chi^{2}$ test.

${ }^{2}$ Juling et al. (2006).

${ }^{3}$ Nakamitsu et al. (2006).

$* P<0.05$. 
Table 3. Frequencies of the 23-bp, 12-bp haplotypes in Holstein cattle

\begin{tabular}{|c|c|c|c|c|c|}
\hline & \multicolumn{5}{|c|}{$23 \mathrm{bp}, 12 \mathrm{bp}$} \\
\hline & $\mathrm{n}$ &,++ &,-+ &,-- & $P$-value ${ }^{1}$ \\
\hline \multicolumn{6}{|l|}{ State } \\
\hline California & 120 & 0.55 & 0.00 & 0.45 & $0.009 *$ \\
\hline Iowa & 350 & 0.45 & 0.05 & 0.51 & 0.796 \\
\hline Minnesota & 88 & 0.31 & 0.08 & 0.61 & $0.028^{*}$ \\
\hline New York & 164 & 0.45 & 0.04 & 0.51 & 0.955 \\
\hline Oregon & 116 & 0.40 & 0.01 & 0.59 & 0.117 \\
\hline Tennessee & 104 & 0.46 & 0.08 & 0.46 & 0.092 \\
\hline Texas & 152 & 0.38 & 0.01 & 0.62 & 0.060 \\
\hline Vermont & 168 & 0.43 & 0.06 & 0.51 & 0.547 \\
\hline Wisconsin & 118 & 0.42 & 0.03 & 0.56 & 0.600 \\
\hline US total & 1,380 & 0.43 & 0.04 & 0.52 & - \\
\hline \multicolumn{6}{|l|}{ Country } \\
\hline Germany $^{2}$ & 615 & 0.38 & 0.09 & 0.53 & $<0.001^{*}$ \\
\hline United Kingdom $^{2}$ & 546 & 0.29 & 0.08 & 0.63 & $<0.001^{*}$ \\
\hline \multicolumn{6}{|l|}{ Archived } \\
\hline US $1950 \mathrm{~s}$ & 20 & 0.35 & 0.20 & 0.45 & $0.003^{*}$ \\
\hline
\end{tabular}

${ }^{1}$ Statistical comparisons between total US population and individual states, countries, and archived samples using the $\chi^{2}$ test.

${ }^{2}$ Juling et al. (2006).

$* P<0.05$.

and no animals were homozygous for 5 octapeptide repeats.

Samples from 10 Holstein sires born in the United States between 1953 and 1957 were genotyped with respect to the 23-bp and 12-bp indel (Tables 1 to 3 ) and sequenced for the PRNP coding region. The only statistical difference between the contemporary US Holstein population and the archived samples was in the haplotype frequencies $(P=0.003)$; there were no differences for the allele and genotype frequencies. Finally, only 2 nucleotide sites had substitutions in the $P R N P$ gene (nucleotides $234 \mathrm{~A} / \mathrm{G}, 576 \mathrm{C} / \mathrm{T}$ ), neither of which was novel compared with contemporary cattle (Seabury et al., 2004). Although 10 archived samples are too few for precise analysis, there does not appear to have been a drastic change in genotype and allele frequencies since the $1950 \mathrm{~s}$, because the archived samples fall within the range observed in present day cattle.

This work reports frequencies of the currently known genetic factors associated with resistance and susceptibility to feedborne BSE for US Holsteins. The frequency of the 23-bp and 12-bp insertions associated with resistance was as high as, or higher than, 3 geographically distinct Holstein populations. Also, no Holstein cattle sampled contained a $P R N P$ gene encoding 7 or more octapeptide repeats. Combined, the data presented indicate that the US Holstein population is not at a greater risk for BSE compared with Holsteins worldwide. In fact, these results suggest that US Holstein cattle are at a lower risk than other Holstein populations analyzed to date. Should this BSE-resistant $P R N P$ genotype prove desirable, it would be relatively easy to increase the prevalence of the insertion alleles among US Holsteins via AI with sires carrying the resistant genotype.

\section{ACKNOWLEDGMENTS}

We would like to thank Megan Westall and Tara McDaneld for their assistance in the collection of buccal swabs from cattle. We would also like to thank Scott Wells for his role in the collection and processing of samples used from the NAHMS 96 study. Finally, we are grateful for the critical evaluation of the manuscript by Eugene Freeman.

\section{REFERENCES}

Barrett, J. C., B. Fry, J. Maller, and M. J. Daly. 2005. Haploview: Analysis and visualization of $\mathrm{LD}$ and haplotype maps. Bioinformatics 21:263-265.

Brunelle, B. W., A. N. Hamir, T. Baron, A. G. Biacabe, J. A. Richt, R. A. Kunkle, R. C. Cutlip, J. M. Miller, and E. M. Nicholson. 2007. Polymorphisms of the prion gene promoter region that influence classical BSE susceptibility are not applicable to other transmissible spongiform encephalopathies in cattle. J. Anim. Sci. 85:3142-3147.

Carlson, G. A., C. Ebeling, S. L. Yang, G. Telling, M. Torchia, D. Groth, D. Westaway, S. J. DeArmond, and S. B. Prusiner. 1994. Prion isolate specified allotypic interactions between the cellular and scrapie prion proteins in congenic and transgenic mice. Proc. Natl. Acad. Sci. USA 91:5690-5694.

Castilla, J., A. Gutierrez-Adan, A. Brun, B. Pintado, B. Parra, M. A. Ramirez, F. J. Salguero, F. Diaz San Segundo, A. Rabano, M. J. Cano, and J. M. Torres. 2004. Different behavior toward bovine spongiform encephalopathy infection of bovine prion protein transgenic mice with one extra repeat octapeptide insert mutation. J. Neurosci. 24:2156-2164.

Castilla, J., A. Gutierrez-Adan, A. Brun, B. Pintado, F. J. Salguero, B. Parra, F. D. Segundo, M. A. Ramirez, A. Rabano, M. J. Cano, 
and J. M. Torres. 2005. Transgenic mice expressing bovine PrP with a four extra repeat octapeptide insert mutation show a spontaneous, non-transmissible, neurodegenerative disease and an expedited course of BSE infection. FEBS Lett. 579:6237-6246.

Geldermann, H., H. He, P. Bobal, H. Bartenschlager, and S. Preuss. 2006. Comparison of DNA variants in the PRNP and NF1 regions between bovine spongiform encephalopathy and control cattle. Anim. Genet. 37:469-474.

Hills, D., S. Comincini, J. Schlaepfer, G. Dolf, L. Ferretti, and J. L. Williams. 2001. Complete genomic sequence of the bovine prion gene $(P R N P)$ and polymorphism in its promoter region. Anim. Genet. 32:231-232.

Hunter, N., W. Goldmann, G. Smith, and J. Hope. 1994. Frequencies of $\operatorname{PrP}$ gene variants in healthy cattle and cattle with BSE in Scotland. Vet. Rec. 135:400-403.

Juling, K., H. Schwarzenbacher, J. L. Williams, and R. Fries. 2006. A major genetic component of BSE susceptibility. BMC Biol. 4:33.

Lange, K., D. Weeks, and M. Boehnke. 1988. Programs for Pedigree Analysis: MENDEL, FISHER, and dGENE. Genet. Epidemiol. 5:471-472.

Manson, J. C., A. R. Clarke, P. A. McBride, I. McConnell, and J. Hope. 1994. PrP gene dosage determines the timing but not the final intensity or distribution of lesions in scrapie pathology. Neurodegeneration 3:331-340.

Nakamitsu, S., T. Miyazawa, M. Horiuchi, S. Onoe, Y. Ohoba, H. Kitagawa, and N. Ishiguro. 2006. Sequence variation of bovine prion protein gene in Japanese cattle (Holstein and Japanese Black). J. Vet. Med. Sci. 68:27-33.
Ott, S. L., S. J. Wells, and B. A. Wagner. 1999. Herd-level economic losses associated with Johne's disease on US dairy operations. Prev. Vet. Med. 40:179-192.

Prusiner, S. B. 1998. Prions. Proc. Natl. Acad. Sci. USA 95:1336313383.

Sander, P., H. Hamann, C. Drogemuller, K. Kashkevich, K. Schiebel, and T. Leeb. 2005. Bovine prion protein gene (PRNP) promoter polymorphisms modulate PRNP expression and may be responsible for differences in bovine spongiform encephalopathy susceptibility. J. Biol. Chem. 280:37408-37414.

Sander, P., H. Hamann, I. Pfeiffer, W. Wemheuer, B. Brenig, M. H. Groschup, U. Ziegler, O. Distl, and T. Leeb. 2004. Analysis of sequence variability of the bovine prion protein gene $(P R N P)$ in German cattle breeds. Neurogenetics 5:19-25.

Sauter-Louis, C., M. Clauss, E. Chaher, W. Klee, H. E. Wichmann, and E. Kienzle. 2006. Breed predisposition for BSE: Epidemiological evidence in Bavarian cattle. Schweiz. Arch. Tierheilkd. 148:245-250.

Schlapfer, I., N. Saitbekova, C. Gaillard, and G. Dolf. 1999. A new allelic variant in the bovine prion protein gene (PRNP) coding region. Anim. Genet. 30:386-387.

Seabury, C. M., R. L. Honeycutt, A. P. Rooney, N. D. Halbert, and J. N. Derr. 2004. Prion protein gene $(P R N P)$ variants and evidence for strong purifying selection in functionally important regions of bovine exon 3. Proc. Natl. Acad. Sci. USA 101:15142-15147.

Wilesmith, J. W., J. B. Ryan, and M. J. Atkinson. 1991. Bovine spongiform encephalopathy: Epidemiological studies on the origin. Vet. Rec. 128:199-203. 